\title{
Ciências da Educação em questão
}

Tarso Mazzotti

Universidade Estácio de Sá

\section{Resumo}

As Ciências da Educação encontram-se em uma 'dispersão epistemológica' (Tardy, 1989), o que não é sua exclusividade, pois isso também ocorre com as Ciências do Homem, uma vez que ambas estão atadas ao programa de cientificidade que retira as pessoas do lugar de produção do conhecimento, tanto no paradigma moderno quanto no pós-moderno. Propõe-se, aqui, uma teoria humanista do conhecimento, na qual as três espécies de silogismo - entimema, dialético e demonstrativo - são consideradas complementares no processo de instituição dos conhecimentos, com base em critérios próprios das metodologias ou regras do fazer ou algoritmos reconhecidos pelos grupos sociais que as sustentam. Tais regras do fazer ou algoritmos não constituem uma lógica natural, uma vez que qualquer lógica é um cálculo. Os algoritmos para a produção de conhecimentos encontram-se na relação inseparável entre o orador (ethos), o auditório (pathos) e o discurso (lógos), na qual são validados os argumentos. Donde, uma teoria humanista do conhecimento permite a sublimação da referida 'dispersão epistemológica', isso porque deixa explícita as situações nas quais um conhecimento é validado. Assim sendo, as metodologias são garantias razoáveis, não determinantes dos conhecimentos confiáveis, pois seus fiadores são os grupos sociais que os admitem e sustentam.

\section{Palavras-chave}

Ciências do Homem - Ciências da Educação - Teoria humanista do conhecimento - Retórica, Dialética e Lógica. 


\section{The Sciences of Education under scrutiny}

Tarso Mazzotti

Universidade Estácio de Sá

\begin{abstract}
The Sciences of Education experience an "epistemological dispersion" (Tardy, 1989), in which they are not alone, for the same happens to the Sciences of Man, both being attached to the program of scientificity that removes people from the place of production of knowledge, be it under the modern paradigm, be it under the postmodern. What is proposed here is a humanist theory of knowledge in which the three kinds of syllogism enthymeme, dialectical, and demonstrative - are regarded as complementary in the process of establishing knowledge, based on criteria proper to the methodologies or rules of doing, or to algorithms recognized by the social groups that give support to them. Such rules of doing or algorithms do not constitute a natural logic, since any logic is a calculation. The algorithms for the production of knowledge are found in the indissoluble relation between the orator (ethos), the audience (pathos) and the discourse (logos), where the arguments are validated. Hence, a humanist theory of knowledge allows the sublimation of the abovementioned "epistemological dispersion", for it makes explicit the situations in which a piece of knowledge is validated. Thus, the methodologies are reasonable guarantees, but do not determine reliable knowledge, because its guarantors are the social groups that admit and support it.
\end{abstract}

\section{Keywords}

Sciences of Man - Sciences of Education - Humanist theory of knowledge - Rhetoric, dialectics and logic. 
A teoria do conhecimento científico ou confiável - ou ainda epistemologia - parte de uma decisão a respeito dos enunciados primeiros, os que dizem respeito à diferença entre as sensações (aisthêsis) e o que se apresenta como sendo a sua verdade. Aristóteles, em Sobre a Alma, apresenta essa posição dos sofistas ao dizer:

Assim como a visão não consiste em conhecer os sons da voz, do mesmo modo a audição não ouve as cores, mas os sons; e, aquele que diz, não põe uma cor nem uma coisa. (De Anima, 980a 18)

A sofística sustentou que estabelecemos pelo discurso uma negociação de significados do que se julga ser algo, que não emerge diretamente das sensações. Cassin (1999, p. 222), em passagem acurada, diz: "Não bebemos jamais aquilo [o vinho] do qual falamos”. Dizemos algo a respeito do vinho, mas não saboreamos o que foi dito. 0 mundo sensível, em Aristóteles, não é sensação, é discurso (lógos), que Cassin (1999) diz ser "lógico, Fenômeno/lógico, ou mesmo lógicofenomenal”. Para ela, Aristóteles é duplamente sofístico: ao se opor a Platão, que sustenta que o ser é, mantendo a posição defendida por Parmênides; e ao afirmar uma tese contrária à idéia de que haja alguma sensação própria ou apropriada, uma vez que "ele fornece, por fim, a prova de que é o lógos como tal, e não a aisthêta (sensação) que performa o mundo" (Cassin, 1999, p. 222). Nesse registro, os enunciados a respeito das coisas do mundo são postos na linguagem, pela negociação de significados, considerando-se que não há ruptura entre pensamento e linguagem, como se quer na maioria das teorias do conhecimento e, particularmente, nas do conhecimento científico ou epistemologias.

0 problema do pensar as sensações e as comunicar amplia-se quando se trata de objetos (conceituais) que envolvem 'processos', que não podem ser verificados a não ser por meio de algum esquema conceitual mais extenso. É o caso da educação, pois essa ação supõe um percurso que conduz o educando do estado de não-educado a outro, aquele em que se o considera educado. Esse processo ou percurso ou currículo sustenta-se em um axioma pedagógico que diz ser possível conduzir o educando do estado de ignorância ao do saber ou outra forma equivalente. Esse axioma, ou hipótese admitida, apresentada na forma modal (é possível), requer que se admita, de partida, a sua impossibilidade, uma vez que 'possível' não é o mesmo que 'necessário', logo nos põe em presença da liberdade da ação humana. 0 processo necessário é, por exemplo, o crescimento orgânico, o que não é o caso da educação, como se sabe. A idéia de processo expressa algo que ultrapassa em muito o sensível, depende de uma certa concepção a respeito do que se realiza sob tais ou quais condições, o que se desenrola, desenvolve-se. Nesse sentido, somos mais ou menos cegos, pois os demais modos de ver (teorias) ou não são consideradas ou as tratamos como adversárias a serem derrotadas por todos os meios. Em ambas as situações, abandonamos o diálogo hostil-amistoso que permitiria uma melhor compreensão do processo dito educacional. Tem razão Charbonnel (1991, p. 12) quando, apoiando-se na distinção entre litígio e disputa, considera que as doutrinas pedagógicas são "máquinas criadoras de litígios intelectuais, bem mais do que para os solucionar".

As Ciências da Educação escapariam dessa constatação? As ciências que examinam e procuram explicar o processo educacional também são modos de ver, são teorias e, como tais, estabelecem o que deve e pode ser visto, aquilo que é posto para nós: o objeto. Mais ainda, no âmbito de cada ciência, há teorias concorrentes, cada qual considerada a melhor dentre elas, assim, de fato, fomentam o litígio. Tem-se uma profusão de teorias produzindo uma multiplicidade de objetos, donde a avaliação de Tardy (1989) de que há uma debandada epistemológica nas Ciências da Educação, evidenciada já pelo próprio nome: "Ciências da Educação", utilizado, na França, para designar as pesquisas e os estudos sobre a educação.

A pluralidade de teorias, a dispersão epistemológica assim estabelecida, seria irrelevante 
caso não tivesse implicações práticas. No entanto, suas implicações são enormes. Consideremos apenas uma delas, a mais evidente, a que se apresenta quando pretendemos formar ou educar professores. Por quais critérios selecionam-se as teorias e as matérias de ensino para formar professores? $\mathrm{Na}$ falta de acordos sobre os critérios, apelamos para o ensino plural, que procura contemplar todas as teorias em uma matéria de ensino, e todas as matérias que um grupo considere adequadas e conforme as possibilidades imediatas dos docentes. Ao final, não se tem como julgar se tal ou qual currículo efetivamente educou os professores.

A dispersão epistemológica das Ciências de Educação expressa, de fato, a das Ciências Sociais ou das Ciências do Homem, na nomenclatura francesa que prefiro. Embora antes delas a Pedagogia já se caracterizasse pela multiplicidade de doutrinas concorrentes, esperava-se que fosse ultrapassada por uma Ciência da Educação (no singular), como a que se pretendeu constituir no início do século XX. Tratar cientificamente a educação, especialmente a educação escolar, procurando constituir um corpus de conhecimentos confiáveis, foi o objetivo de muitos que se dedicaram ao assunto. No entanto, a partir da segunda metade daquele século, o projeto extinguiuse por insuficiência conceitual das ciências nas quais se apoiava. Resta, pois, a dispersão epistemológica e, com ela, repõem-se alguns problemas epistemológicos.

\section{Insuficiência das Ciências do Homem ou do homem?}

A insuficiência conceitual das Ciências do Homem expressa a do homem? Seríamos incapazes de formular conceitos adequados ou pertinentes à nossa condição? Caso os limites das Ciências do Homem decorram de uma irremediável insuficiência humana, de nossa própria condição, então não há saída, pois a pluralidade teórica é sua expressão, pouco ou nada podemos fazer. Qualquer teoria sobre o homem tem igual valor de verdade, todas defensáveis, nada podemos esperar do debate entre seus defensores, salvo a querela, o litígio. Nesse caso, torna-se defensável uma trégua na guerra das doutrinas ou paradigmas, tal como se quer no caso das religiosas, pois o convívio é uma imposição da vida social regulada pela democracia. Ao mesmo tempo, cada grupo buscará mais e mais adeptos, sendo que os mais hábeis acabarão por dominar uma instituição e, eventualmente, muitas outras instâncias da sociedade. Os dominantes aparecem como os que detêm a verdade, o correto, embora o façam pela aniquilação do debate regulado próprio da democracia (cfr., entre outros, Kuhn, [1962] 1996; Ross, 1996). Eis porque Charbonnel (1991b) sustentou que a investigação das pedagogias seria mais certeira caso adotasse a metodologia da Sociologia das Religiões. De fato, se não há como estabelecer algum critério para a constituição de conhecimentos confiáveis sobre a educação, resta tomar uma posição doutrinária, como aquela autora constatou em seus trabalhos (Charbonnel 1993; 1991a; 1991b). Sendo assim, caberia investigar as disputas entre as pedagogias como se faz com as das religiões. Por seu lado, Reboul (1984, p. 9) considera que o "discurso pedagógico é o mais ideológico de todos os discursos. Mais ideológico do que o discurso político, pelo menos em nossa época”. Haveria, então, como ultrapassar seu caráter doutrinário? Esperava-se isso por meio de uma Ciência da Educação ou da Pedagogia, no sentido utilizado por E. Durkheim. Todavia, o ideal regulatório daquela ciência esvaiu-se logo nas primeiras décadas do século XX (cfr., por exemplo, Boudon, 1998; 1990).

Aquele ideal vinculava a razão ou a racionalidade à lógica entendida como um sistema de regras e normas do bem pensar, independentes do conteúdo. Com o desenvolvimento da análise dos processos de inferência formal, especialmente os utilizados nas Matemáticas, ficou claro que a lógica é um sistema de cálculos que independe de quem a realiza. A partir daí, os trabalhos de formalização da lógica mostraram que, para ser bem formada, precisa abandonar qualquer suposição sobre as operações mentais e, com 
isso, livrou-se de qualquer aspecto que tenha referência no psiquismo. As operações lógicas só podem ser lógicas, ou seja, os operadores 'e', 'ou', ' $\rightarrow$ ' (condicional) expressam modos de pôr em relação os enunciados apresentados como 'variáveis', ou seja, algo cujo referente é vazio, uma vez que pode ser preenchido por qualquer conteúdo. A lógica, compreendida como cálculo, buscou encontrar seu fundamento em si mesma, ou seja, mostrar-se completa. No entanto, ao procurar estabelecer a completude da lógica da aritmética, portanto a mais elementar ou fundamental, Gödel ([1931] 1992) demonstrou que ela não é completa, uma vez que recorre a axiomas extralógicos. 0 programa de formalização integral das Matemáticas mostrouse inviável e abriu os horizontes dos matemáticos, que agora, como diz Da Costa $(1997 ; 1980)$, sabem que trabalham em uma atividade livre. Os constrangimentos formais são válidos em uma lógica, mas podem ser derrogados em outras, criando-se novas lógicas bem formadas, como a paraconsistente estabelecida por Da Costa. No centro mesmo do programa de formalização das ciências, chegou-se à sua derrogação. Donde, não há porque confundir racionalidade ou razão com uma e uma só lógica, uma vez que há várias bem formadas a serem escolhidas para tratarem desse ou daquele objeto. A escoIha da lógica pertinente torna-se, pois, uma das tarefas fundamentais dos pesquisadores em qualquer área do conhecimento, da mesma maneira que os físicos escolhem a geometria que julgam adequada aos temas que estão tratando.

Enquanto as ciências Lógica e Matemática reviam seus programas de pesquisa, e algumas outras faziam o mesmo, as Ciências do Homem continuaram buscando uma teoria unificadora formal que permitisse tratar seus temas de maneira a restringir ao máximo o papel do pesquisador. Não pretendo fazer História da Ciência, apenas indico o que ocorreu, ilustrando por meio de um programa de unificação das Ciências do Homem, o proposto pelo Estruturalismo (cfr., por exemplo, Dose, 1994; 1993). Esse programa considera que a língua fala o homem, como se a língua fosse uma máquina não-física, uma máquina matemática, um cálculo. Assim considerando, não há ator social, não há sujeito, uma vez que as ações dos homens são o resultado de um processo para além ou aquém do humano e decorrem da estrutura. Opõe-se à concepção que sustenta que o homem fala a língua, bem como a uma outra maneira de ver, mais nuançada, a que afirma que o homem fala e é falado pela língua. Tais concepções não são novas na história do pensamento, encontram-se, com variações, nos primeiros embates da Grécia Antiga.

A noção de que somos marionetes dos deuses e, ao mesmo tempo, procuramos cooptá-los, encontra-se na llíada e Odisséia, nas quais podemos apreender o papel da técnica ou arte de argumentar de Ulisses que, por sua habilidade, produz alterações fundamentais no curso dos eventos, utilizando-se da astúcia, da palavra certeira, dos argumentos que desmontam as tramas urdidas pelos deuses que disputam entre si por meio dos homens. Ulisses fala e é falado, sua língua é a dos homens, do grupo social no qual se faz homem, mas não se limita a ela, produz novos fatos, altera o curso dos eventos, por atos e palavras, sempre orientado, mas não determinado, por Palas Atenas. Ulisses é o humano que, pela palavra, produz mudanças na vida social, expressão do papel do orador bem formado, ideal da Grécia democrática, na qual as leis e normas não são nem divinas nem naturais, mas humanas, muito humanas.

No entanto, a arte de conduzir os homens pelo discurso foi considerada simples astúcia, técnica da mentira, dos demagogos. Era preciso, afirmava Platão, substituí-la por outra, por uma certa dialética, a que se faz pela apreensão do essencial que se encontra no âmago de cada um. Entretanto, nem todos têm em si a verdade, os que a possuem revelam-na no curso de sua existência, são os 'amigos do saber', os filósofos, que devem governar por terem a palavra verdadeira. Sustenta-se, assim, uma retórica divina, a dos homens que contemplaram a verdade, a palavra incontestável. Se os 
deuses não dirigem os homens, então os amigos da sabedoria, os que contemplaram a verdade antes de nascerem, devem dirigi-los, cabendo ao processo educativo encontrá-los. Essa maneira de ver foi amplificada pelo cristianismo que pretende ter recebido a palavra verdadeira diretamente do Filho de Deus, restando ao homem aplicá-la à vida comum. As divergências em torno da interpretação correta daquela palavra produziram e ainda produzem querelas, litígios. A solução dos litígios esteve, por muito tempo, nas mãos da lgreja Católica, que determina a palavra correta aos seus fiéis. No interior mesmo do cristianismo, no século XVl, desenvolveu-se um certo ceticismo em relação à correção das interpretações estabelecidas pelo clero católico, que produziu uma ruptura que marcou a vida moderna, a protestante, cujo porta-voz mais ouvido foi Martinho Lutero (Popkin, 2000). Este, mesmo não desejando, instalou no interior da doutrina cristã a atitude cética, cuja solução de compromisso está na afirmação de que cada um tem em si as luzes necessárias para interpretar a Palavra de Deus. A retórica, agora, é inspiração que se manifesta em cada um conforme sua pureza ou capacidade, uma vez que Deus fala por meio dos homens e, por essa via, institui a vida social (Millet, 1999). 0 que parece, em um primeiro momento, a libertação definitiva das lições ou dos dogmas cristãos é a expressão de uma concepção de que o Espírito a todos conforma. Tal doutrina ganhou maior amplitude e exposição conceitual na filosofia de Hegel, na qual o espírito-do-povo (Volksgeist) nos condiciona, nos conforma, cabendo saber o que ele é para nos ajustarmos, o melhor possível, aos seus desígnios. 0 homem é livre quando compreende o necessário para a vida social moldada pelo espírito-do-povo, a figura de Deus ou Espírito Absoluto no mundo.

As doutrinas acima se encontram no horizonte das Ciências do Homem. A noção de que a língua fala o homem, tal como se encontra no Estruturalismo, é sua face naturalizada, pela qual a estrutura social determina por inteiro a vida humana. Mesmo em sua forma mais recente, a dita pós-estruturalista ou pós-moderna, encontramos o programa formalista que presidiu a busca dos fundamentos da Matemática, como mostrou Tasiè (2001). 0 programa dito pósmoderno ou pós-estruturalista considera Descartes seu adversário, no entanto, busca realizar o que ele propôs em seu Discurso do método para bem conduzir sua razão e buscar a verdade nas ciências (Discours de la méthode pour bien conduire sa raizon et checher la verité dans les sciences). Seu método é o demonstrativo, expressão utilizada por Euclides em seus Elementos de Geometria, que prescinde o sujeito, a pessoa, uma vez que é um cálculo a partir de axiomas ou postulados. Por essa via, realiza-se a "eutanásia simbólica do sujeito humano” (Tasiè, 2001, p. 79), cara ao que se tem denominado pós-modernismo ou pós-estruturalismo. Os postulados, que se encontram na base dos encadeamentos demonstrativos, originam-se de alguma intuição, sobre a qual muito se fala e pouco se diz. Como veremos a seguir, a restauração da Retórica enfrenta essa questão sustentando que o homem fala e é falado pela língua, que a razão não se confunde com a demonstração ou com a Lógica.

\section{Restauração da retórica}

Ao lado e independente do programa estruturalista, surgiram simultaneamente duas obras que restabeleceram a retórica e a argumentação na esteira da revisão criteriosa da obra de Aristóteles iniciada nas primeiras décadas do século XX (cfr., por exemplo, Berti, 1997). Na Bélgica, Chaïm Perelman e Lucie Olbrechts-Tyteca (1996) publicaram o Tratado da Argumentação: a nova retórica; na Inglaterra, Stephen Toulmin (2001) deu a conhecer seu Os usos do argumento, ambas no mesmo ano de 1958. Tanto Perelman quanto Toulmin têm a mesma origem intelectual, trabalharam com afinco no programa de formalização da lógica, abandonaram aquele programa de pesquisa por insuficiente, desde o teorema de Gödel sobre a incompletude da aritmética. Buscaram outra via 
para compreender o processo de constituição dos conhecimentos e, para isso, recorreram a uma revisão do Órganon de Aristóteles, nele incluindo a Retórica. Para eles, a racionalidade não é insuficiente per se, salvo quando se afirma a identidade entre uma certa lógica - a demonstrativa - e a razão. Outras racionalidades permitem o exame acurado das situações e, embora não permitam sustentar enunciados apodícticos ou categóricos, fornecem critérios para decidirmos a respeito de suas qualidades argumentativas. 0 diálogo requer - como mostraram os Sofistas (Kerferd, 2003) e, depois deles, Aristóteles - algumas regras éticas, as próprias da isonomia, as da democracia, na qual os cidadãos são considerados capazes de deliberar. Há por certo algumas limitações. Se nos assuntos éticos ou políticos todos têm igual competência, em outros, como no caso das técnicas (artes) e das ciências, só os mais sábios podem efetivamente deliberar. A assembléia pode legitimamente decretar guerra, mas os generais devem ser escolhidos entre os mais hábeis, assim como na escolha de capitães de navio, na do médico, bem como na de um mestre-de-obra. Os mais sábios em uma arte ou em alguma ciência constituem opiniões comuns ou prováveis - éndoxon - que podem ser contestadas por outros de igual qualidade. Os que ignoram uma ciência ou técnica mostram seu estado ao contradizerem seus enunciados, em tais casos só resta enviá-las à 'escola' para que aprendam o que não sabem.

A situação retórica, no sentido de sua recuperação por Perelman, envolve o orador (ethos), o auditório (pathos) e o discurso (lógos) e não pode prescindir de nenhum deles. Não pode fixar-se no lógos, pois cairia no exame estrutural per se, que conduz às aporias do formalismo. Não se fixa nem no ethos nem no pathos, caso contrário mergulharia em uma busca ou da psicologia do indivíduo ou na do coletivo que, no limite, fazem desaparecer a relação de persuasão e deliberação. Nem o orador (escritor, emissor) persuade o auditório (coletivo, massa, grupo social) por inteiro como bem entende nem este é isento em suas adesões, uma vez que reconhece e produz o orador que considera seu porta-voz ou autoridade (Meyer, 1999; 1986; Reboul, 1998; dentre outros). 0 auditório universal é um ideal regulatório para o orador, na prática, os auditórios são particulares que reconhecem os oradores segundo seus critérios.

Dentre os golpes certeiros desferidos por Perelman e Olbrechts-Tyteca, destaco um, pois desloca da lógica para a retórica um erro capitulado na primeira. Trata-se da petição de princípio, que Aristóteles tratou tanto nos Tópicos quanto nos Analíticos, definida como sustentar de início o que se quer provar. Perelman e Olbrechts-Tyteca (1996) dizem que:

[...] no plano da lógica formal a acusação de petição de princípio é desprovida de sentido. Poder-se-ia, de fato, pretender que toda dedução formalmente correta consiste numa petição de princípio, e o princípio da identidade, que afirma que toda proposição implica a si própria, seria mesmo a petição de princípio formalizada. De fato, a petição de princípio, que não diz respeito à verdade, mas à adesão dos interlocutores às premissas que se pressupõem, não é um erro de lógica, mas de retórica; é compreendida, não no interior de uma teoria da demonstração, mas relativamente à técnica argumentativa. (p. 127)

Compreender a petição de princípio como um erro retórico, pois depende exclusivamente dos interlocutores, dos auditórios, implica uma revisão profunda no que se propõe ser a base da racionalidade. Considera-se que certos enunciados são admissíveis para alguns auditórios e inadmissiveis para outros, sem que se tenha um modo automático para decidir quem tem razão nos conduz a repensar as bases das epistemologias correntes. Foi o que fizeram Perelman e Toumin ao restaurarem a retórica e a argumentação, expondo as racionalidades segundo as situações sociais, abrindo o caminho para investigações que examinem as condições próprias daquelas técnicas, bem como para verificar os critérios da análise retórica e argumentativa. 
As Ciências do Homem, conseqüentemente as da Educação, podem superar a dispersão epistemológica por meio da revisão de seus postulados sobre o próprio do homem, retomando, em sua radicalidade, o significado de o homem ser, como definiam os gregos, Zôom lógon ékhon - animal que tem a palavra -, do qual tem prevalecido seu significado derivado: animal racional. Esse animal, que tem a palavra, exercita-se na pólis, é um animal político ou social, que se reconhece como animal, natureza, e ao mesmo tempo não-animal, um ser produzido e que produz sua vida social - política, no sentido grego - por meio do discurso em praça pública, na ágora. Não é apenas um ser que fala, pois o escravo - homem não-político, pois não responsável por seus discursos - também fala. A fala propriamente humana é a que responde pelo que diz - responsável - na assembléia que delibera sobre o futuro; no tribunal, que julga o passado; nos eventos festivos ou de consternação, quando censura ou elogia, reafirmando valores, três situações determinam os três gêneros da retórica: deliberativo, judiciário e epidítico.

Em uma outra situação, na do diálogo entre pessoas ou consigo mesmo, examinam-se argumentos contraditórios para verificar qual deles é admissivel. Se é factível combiná-los em um terceiro ou abandonar a ambos, trata-se da situação dialética descrita por Aristóteles nos Tópicos e Refutações Sofísticas.

Por fim, há a situação em que se ensina o que se alcançou por meio do diálogo, da dialética, quando se expõe uma ciência, um conhecimento considerado confiável pelos mais sábios. Nessa situação, é preciso partir de axiomas ou hipóteses admitidas pelos mais sábios e encadear o raciocínio de maneira tal que cada um leve ao outro, sem contradições. Aristóteles denominou demonstração, descrita nos Analíticos anteriores e posteriores, a situação de ensino.

Ao longo da história do pensamento ocidental, os Analíticos foram considerados o modelo do pensar correto, desprezando-se as demais artes ou técnicas, vindo a instituir a identidade entre razão e o que a escolástica denominou lógica. Atualmente, após a revisão da ciência Lógica, e da restauração dos estudos e investigações retóricas e argumentativas, não há mais por que manter aquela identidade. Repor os homens em suas situações, que se institucionalizam, no centro da produção e reprodução de saberes e conhecimentos, permite a ultrapassagem das teorias que afirmam que a língua fala o homem. lsso porque, o homem fala e é falado pela língua, o que requer investigações que ultrapassem a polaridade entre o coletivo e o individual, por considerar que se trata de uma relação psicossocial ou retórica. Certamente, as exigências são maiores. Não basta afirmar as características pessoais, bem como as dos grupos sociais, pois um e outro não são separáveis, salvo em certos estudos que viabilizem a compreensão de alguns processos particulares, como se faz na Psicologia cognitiva.

\section{Procurando sublimar (Aufheben) a dispersão epistemológica}

A sublimação da dispersão epistemológica das Ciências da Educação requer a das Ciências do Homem, que não ocorrerá automaticamente pela incorporação da retórica e da argumentação, isso porque é preciso estabelecer seus objetos, como no caso da Educação (Pedagogia).

Uma vez que cada teoria institui o objeto, qual o próprio da Pedagogia ${ }^{1}$, condição reflexiva da educação? É razoável considerar educação uma palavra-valise com tal grau de ambigüidade que comporta múltiplos assuntos, os quais são objetos de cada teoria que se queria testar ao investigar o processo educativo. Seria um caso do ser que se diz de múltiplas maneiras. Temos, então, um problema: como ultrapassar a dispersão epistemológica das Ciências de Educação se educação é uma palavra ambígua, uma palavra com

1. Adoto a palavra 'Pedagogia' para designar o conjunto de saberes a respeito da 'educação', procurando evitar a confusão entre o fazer e o que se diz a seu respeito. Todavia, uma outra se põe com o Curso de Pedagogia. Aqui não se trata do curso, mas daquele conjunto de saberes. 
múltiplos referentes? Fixar o sentido da palavra é um ato arbitrário ou a falácia da definição estipulativa. Recortar significados para obter objetos tratáveis por esta ou aquela teoria é continuar a dispersão epistemológica, pois implica uma decisão prévia a respeito da teoria considerada válida, sem que isso tenha sido estabelecido. Utilizar as técnicas originárias da retórica e da argumentação permite o exame dos discursos pedagógicos, mas não viabiliza, de imediato, a constituição de algum objeto próprio da Pedagogia. No entanto, tal análise, que associa a argumentação e a analítica, permite a exposição de um conjunto de enunciados sobre a educação que viabiliza o diálogo cooperativo entre os pesquisadores, os que trabalham nas Ciências da Educação. Esse o papel da Filosofia da Educação proposto por Mazzotti e Oliveira (2000).

No entanto, ao que parece, nenhuma das alternativas anteriores viabiliza a superação da dispersão de nossas ciências, sendo preciso verificar qual é o impedimento. Este se encontra em nossa concepção sobre a inferência ou silogismo considerado científico, e que nos colocou nesse círculo de má finitude. É preciso dar mais uma volta no parafuso, pois a raiz do problema, o lugar do impedimento, não se encontra nos silogismos e suas formas, mas em uma certa concepção de lógica natural ou lógica informal a partir da qual aqueles são estabelecidos.

Supõe-se a existência de uma lógica natural, própria do senso comum, que se diferencia da lógica formal por apresentar erros, enganos, falácias, sofismas. Dessa maneira, a lógica natural é estabelecida por contraste com a formal, expondo suas deficiências, as que as pessoas comuns apresentam, por estarem dominadas por aquela. Por contraste, os enunciados que seriam próprios da lógica informal não são lógicos, são erros, falácias, enganos. Supõe-se que tal não ocorre com os cientistas, mesmo que a história das ciências seja a exposição da adesão a sofismas, enganos, falácias e erros. Há, então, um problema freqüentemente aventado e raramente enfrentado: o da lógica natural. Esta, de meu ponto de vista, precisa ser esclarecida, uma vez que sustenta um argumento subentendido nas Ciências do Homem: a lógica usual, a do senso-comum, não é a mesma utilizada nas ciências e filosofias, é uma outra lógica... 'ilógica', irracional.

\section{Problema básico: a lógica natural}

Em trabalho recente, Mazzotti (2003) propôs uma maneira de ver o procedimento denominado ‘abdução' por C. S. Peirce, considerando-o próprio do silogismo retórico ou entimema, pois se sustenta no signo ou índice para realizar uma inferência. 0 signo é um tema próprio da retórica desde os primeiros trabalhos que temos conhecimento. 0 exemplo clássico, que parece ter sido usado por Coráx (século $\mathrm{Vl}$ a.C.), é o do leite como signo de que uma mulher deu à luz. 0 orador não precisa mostrar que uma mulher deu à luz, caso saiba que ela seja lactante. 0 signo sustenta um argumento dependente da experiência das pessoas em geral, permitindo não recorrer a outras provas extratécnicas ou extra-retóricas, pois, ao ser apresentado a inferência, segue-se por si: "Se esta mulher tem leite, então..."

Em algumas situações, é factível construir um bom argumento a partir de um signo, desde que o auditório considere-o bem ajustado à realidade; enquanto que, em outras, os índices parecem impróprios, sendo alvo de disputas, podendo demolir o argumento. Para o que interessa, aqui é suficiente dizer que, a partir de entimemas (silogismo retórico), é factivel transitar para os argumentos demonstrativos, desde que sejam expostas as causas ou as razões pelas quais tais ou quais argumentos devem ser aceitos. No caso do leite como signo de que a mulher deu à luz, basta dizer que a causa da lactação é a gravidez, construindose um silogismo demonstrativo. No entanto, rigorosamente, ainda permanece sendo um argumento retórico, pois se sustenta em um signo que requer melhor explicação (Wolff, 1995). Essa melhor explicação realiza-se em uma situação dialética e, quando se obtém algum co- 
nhecimento confiável, ele pode ser ensinado; antes, porém, é preciso passar pelo crivo da análise silogística ou demonstrativa.

Esse conjunto de procedimentos ou metodologias tem sido considerado a expressão de alguma lógica natural (Mazzotti; Oliveira, 2000). No entanto, aqueles procedimentos não podem ser considerados 'lógicos', uma vez que não são um modo de calcular a validade dos enunciados. Considero que uma metodologia é um conjunto de regras que expressam o que a comunidade verificou serem enganos ou erros a serem evitados. A metodologia não é, de fato, uma lógica, ainda que dela se utilize nem é uma epistemologia, mesmo que se sustente em alguma. É um conjunto de regras orientadas tanto pela lógica quanto pela epistemologia, não se reduzindo nem a uma nem a outra (cfr., por exemplo, Piaget, 1967).

A diferença entre os cientistas e os não-cientistas a respeito de um mesmo assunto está nas regras ou nos modos de produzir evidências, não na lógica que operam. Certamente, o rigor requerido em uma comunidade - por exemplo, a dos cientistas ou a dos nãocientistas - quando tratam de um assunto, determina a qualidade das explicações que apresentam. No entanto, os silogismos, a forma argumentativa básica, é a mesma, bem como seus sofismas, suas falácias e outros enganos. 0 rigor - concisão e conclusividade - refere-se à qualidade das premissas, o que se admite por demonstrado, como salientei ao evidenciar que a petição de princípio como um erro retórico; bem como a supressão de erros lógicos, isso em contextos apropriados, ou seja, segundo as necessidades socialmente estabelecidas. As premissas originam-se de um processo de predicação, de instituição de categorias ou predicados, portanto de metaforização, como mostraram Tort (1989), Ortony ([1979] 1998) e Black ([1963] 1972), por exemplo. Não cabe aqui um exame detalhado da origem das premissas. Parece-me suficiente reafirmar que o modo de fazer para obter conhecimentos confiáveis é inteiramente dependente dos critérios estabelecidos pelos grupos sociais, sejam estes os de não-cientistas ou de cientistas, não havendo diferenças no que se refere ao procedimento lógico, mas há no estabelecimento das premissas das inferências regra da petição de princípio. As exigências argumentativas são as mesmas em ambos os grupos, ainda que, no geral, as falácias e os sofismas sejam admitidos pelos não-cientistas com maior freqüência do que pelos cientistas, o que depende das exigências postas pela situação psicossocial (Mazzoti, no prelo).

\section{Conclusão}

Propor que as Ciências do Homem, nelas incluídas as da Educação, realizem uma virada teórica que considere o que sabemos sobre as técnicas retórica e argumentativa é considerar factível a superação a debandada epistemológica em que nos encontramos.

No entanto, para realizar o pretendido, não basta tomar para si aquelas técnicas, uma vez que é preciso estabelecer uma teoria humanista do conhecimento. Tal teoria sustenta-se na afirmação de que o homem fala e é falado pela língua, apoiando-se na relação clássica da retórica em que o ethos-pathos-logos - ou o orador, o auditório e o discurso - encontram-se unidos de maneira inextricável. 0 orador ou escritor é autorizado pelo auditório ou pelos leitores, é uma autoridade porque os ouvintes assim o consideram. Fixar o exame dos embates sociais em qualquer um dos pólos da relação retórica nos conduz a uma das aporias nas quais nos encontramos.

Para o estabelecimento de uma tal teoria, é preciso considerar que a chamada lógica natural não é uma lógica, mas um modo de fazer, um conjunto de procedimentos que visam estabelecer os conhecimentos. Proponho que se considere tal conjunto de procedimentos um algoritmo, uma vez que tal nomenclatura e conceito permitem que compreendamos a relação fundamental da produção do conhecimento em qualquer área (Berlinski, 2002). Desse ponto de vista, as metodologias científicas, 
assim como as demais, são algoritmos, são receitas que estabelecem os modos de fazer. A gênese de tais receitas pode ser rastreada de maneira simples: cada regra metodológica diz o que não deve ser feito, pois em outras ocasiões constatou-se os enganos e erros cometidos por se ter agido de outra maneira (Mazzotti, 2004).

A teoria humanista do conhecimento não descarta o homem, o sujeito, a pessoa na relação de produção, seja esta qual for. Não busca substituir o homem por algum mecanismo ou cálculo, como se fez Descartes, e que permanece presente nas epistemologias contemporâneas. Radicalmente afirma que o homem é um animal político, quando responsável por seu discurso. Ao mesmo tempo, considera que a descentração do sujeito é condição tanto para a vida política - a democra- cia requer que ultrapassemos os limites de nossa subjetividade - quanto para produzir conhecimentos confiáveis. Afirma a radicalidade do diálogo hostil-amistoso requerido desde o estabelecimento das premissas de alguma inferência - seja qual for a espécie de silogismo - até a verificação das proposições em disputa, quando em uma situação dialética, a que requer o cuidadoso exame de enunciados contraditórios, dos sofismas e das falácias utilizando-se o instrumental analítico ou demonstrativo. Uma teoria do conhecimento não pode reduzir-se a um dos instrumentos para a constituição e análise dos argumentos, uma vez que todos eles são requeridos nas diversas situações, donde afirmar que os procedimentos metodológicos ou algoritmos metodológicos contêm e ultrapassam cada um deles.

\section{Referências bibliográficas}

BLACK, M. Models and metaphors: studies in language and philosophy. Ithaca e Londres: Cornell University Press, 1972 [1963].

BERLINSKI, B. 0 advento do algoritmo: a idéia que governa o mundo. São Paulo: Globo, 2002.

BERTI, E. Aristóteles no século XX. São Paulo: Loyola, 1997.

As razões de Aristóteles. São Paulo: Loyola, 1998.

BOUDON, R. L'art de se persuader des idées douteuses, fragiles ou fausses. Paris: Fayard, 1990.

0 justo e o verdadeiro: estudos sobre a objectividade dos valores e do conhecimento. Lisboa: Instituto Jean Piaget, 1998.

CHARBONNEL, N. Philosophie du modèle. Stasbourg: Presses Universitaires de Strasbourg, 1993.

Les Aventures de la métaphore. Strasbourg: Presses Universitaires de Strasbourg, 1991a.

L'Important, c'est d'etre propre. Strasbourg: Presses Universitaires de Strasbourg, 1991b.

CASSIN, B. Aristóteles e o logos: contos da fenomenologia comum. Tradução L. P. Rouanet. São Paulo: Loyola, 1999.

DA COSTA, N. C. A. Ensaio sobre os fundamentos da lógica. São Paulo: Hucitec, 1980.

Logiques classiques et non classiques: essai sur les fondements de la logique. Paris: Masson, 1997.

DOSE, F. História do estruturalismo. São Paulo: Ensaio/Editora da Unicamp, 1993. (Movimento de idéias/ldéias de movimento, v. 1. "O campo do signo, 1945 a 1966").

História do estruturalismo. São Paulo: Ensaio/Editora da Unicamp, 1994. (Movimento de idéias/ldéias em movimento, v. 2. "O canto do cisne, de 1967 aos nossos dias".).

GÖDEL, K. On formally undecidable propositions of principia mathematica and related systems. New York: Dover Publications, 1992 [1962] 
KERFERD, G. B. 0 movimento sofista. São Paulo: Loyola, 2003.

KUHN, T. S. The structure of scientific revolutions. Chicago; London: The University of Chicago Press, 1996, 3. ed. [1962].

MAZZOTTI, T. B. The rhetoric turn. In: SHOOK, J. (Ed.). Pragmatism, education, and children: international philosophical perspectives. No prelo.

. Lógica natural ou algoritmo? Rio de Janeiro, Educação e Cultura Contemporânea, v. 1, n. 2, ago./dez. 2004, p. 61-79.

Pragmatismo/pragmaticismo: um método para o filosofar. Marília: Centro de Estudos em Filosofia Americana, Filosofia Americana. v. 1, n. 1, p. 67-80, 2003.

. L'analyse des méthaphores: une approche pour la recherche sur les représentations sociales. In: GARNIER, C.; DOISE, W.

(Dir.). Les représentations sociales: balisage du domaine d'études. Montreal: Éditions Nouvelles, 2002, p. 207-226.

MAZZOTTI, T. B.; OLIVEIRA, R. J. Ciência(s) da Educação. Rio de Janeiro: DP\&A, 2000.

MEYER, M. (Dir.) Histoire de la rhétorique des grecs à nous jours. Paris: Le Livre de Poche, 1999.

. De la problematologie: philosophie, science et langage. Bruxelas: Pierre Mardaga Éditeur, 1986.

MILLET, O. La réforme protestante et la rhétorique (circa 1520-1550). In: FUMAROLI, M. (Dir.). Histoire de la rhétorique dans

I'Europe moderne, 1450-1950. Paris: Presses Universitaires de France/ Centre National du Livre, 1999, p. 191-258.

ORTONY, A. Metaphor and trought. 2. Ed. Cambridge: Cambridge University Press, 1998 [1979].

PERELMAN, C.; OLBRECHTS-TYTECA, L. Tratado da argumentação: a nova retórica. São Paulo: Martins Fontes, 1996 [1958].

PIAGET, J. L'epistemologie et ses variétés. In: PIAGET, J. (Dir.). Encyclopédie de la plêiade: logique et connaissance scientifique. Paris: Gallimard, 1967, p. 3-132.

POPKIN, R. História do ceticismo de Erasmo a Spinoza. Rio de Janeiro: Francisco Alves, 2000.

REBOUL, O. Le langage de l'éducation. Paris: PUF, 1984.

REBOUL, 0. Introdução à retórica. Tradução Ivone Castilho Benedetti. São Paulo: Martins Fontes, 1998.

ROSS, A. Science wars. Durham; London: Duke Univeristy Press, 1996.

TARDY, M. De la pédagogie aux sciences de l'éducation. Encyclopédie Philosophique Universelle. L'Univers Philosophique. Paris: Presses Universitaire de France, p. 1282-1287, 1989.

TORT, P. La raison classificatoire: quinze études. Paris: Aubier, 1989 (Série Résonnances).

TASIË, V. Mathematics and the roots of postmodern thought. New York: Oxford University Press, 2001.

TOULMIN, S. Os usos do argumento. São Paulo: Martins Fontes, 2001 [1958].

WOLFF, F. Trois techiniques de vérité dans la Grèce classique: Aristote et l'argumentation. Hermes: Cognition, Communication et Politique, Paris: CNRS, v. 15, n.1, p. 41-72, 1995.

Recebido em 12.05.06

Modificado em 27.09.06

Aprovado em 06.11 .06

Tarso Mazzotti é doutor em Educação pela USP, professor titular de Filosofia da Educação pela UFRJ (aposentado), Professor no Mestrado em Educação da Universidade Estácio de Sá. Publicou artigos em periódicos nacionais e internacionais, capítulos de livros e, com Oliveira "“Ciência(s) da Educação". É membro do Comitê de Periódicos do INEP. 